\title{
NEXUS 1492: ENCUENTROS DEL NUEVO MUNDO CON UN MUNDO EN GLOBALIZACIÓN
}

\section{NEXUS 1492: New World Encounters in a Globalising World}

\section{Corinne L. Hofman}

Facultad de Arqueología. Universidad de Leiden, Holanda. Correo-e: c.l.hofman@arch.leidenuniv.nl ORCID: 0000-0003-4447-5019

\author{
Jorge Ulloa Hung \\ Instituto Tecnológico de Santo Domingo (INTEC), \\ Museo del Hombre Dominicano, República Dominicana \\ Facultad de Arqueología. Universidad de Leiden. \\ Correo-e: jorge.ulloa@intec.edu.do \\ ORCID: 0000-0002-2680-1530
}

Cómo citar: Hofman, C. L., \& Ulloa Hung, J. (2019). NEXUS 1492: Encuentros del Nuevo Mundo con un mundo en globalización. Ciencia y Sociedad, 44(4), 95-115. https://doi.org/10.22206/cys.2019.v44i4.pp95-115

\section{El Caribe: un espacio de movilidad e intercambio}

En 1492, el Caribe era el lugar de habitación de una pluralidad de sociedades insulares cuyos antepasados habían emigrado entre 8000 y 6000 ańos antes desde regiones costeras de Sur y Centro América (Boomert, 2000; Keegan \& Hofman, 2017). Al momento de las incursiones europeas, el Mar Caribe era escenario de redes sociales que evidencian patrones generales de migración, movilidad e interacción entre sus habitantes insulares y los del continente (Hofman, Bright \& Ramos, 2010; Rodríguez Ramos, 2010). Esas redes, incluían el movimiento de personas, bienes, objetos, ideas, palabras, creencias, etc. y fueron transformadas bajo las imposiciones y necesidades del régimen sociopolítico colonial. Estas antiguas redes fueron utilizadas, manipuladas, reforzadas o interrumpidas, según los propósitos de los colonizadores europeos (Hofman, 2019; Hofman, Mol, Hoogland \& Valcárcel Rojas, 2014; Valcárcel Rojas, Samson \& Hoogland, 2013), y constituyeron las bases para el llamado intercambio colombino (Keehnen, Hofman \& Antczak, 2019) en el que el flujo de personas, bienes e ideas a través del Atlántico transformó al mundo en un verdadero mundo globalizado.

\section{El Caribe. Puerta de entrada a la colonización de} Las Américas

El Caribe, fue el puerto de entrada a un universo de riquezas que permitiría la construcción del mayor imperio colonial del siglo XVI, y fue donde por primera vez se desarrollaron las dinámicas interculturales entre amerindios-europeos y africanos. La colonización del Caribe también generó ajustes y transformaciones en la cultura y sociedad de las comunidades indígenas y a su vez sirvió de experiencia y espacio de adaptación y transformación a las viejas políticas y mecanismos de dominación colonial desarrollados por España durante el periodo de reconquista de la península ibérica (Steven Arroyo, 1993).

La estrategia de expansión colonial medieval, caracterizada por la repoblación y la iniciativa privada, fue modificada o suplantada, de manera gradual, por una de confrontación imperial en las conquistas 
coloniales españolas en el Atlántico, especialmente de las Islas Canarias y el Caribe. Esta nueva estrategia enfatizaba en el monopolio y control de las nuevas tierras por el Estado, por tanto, era la Corona española quien las confería a modo de recompensa, lo que implicó un rejuego entre conquista y asentamiento donde se mantuvieron vestigios del antiguo sistema feudal (Tejera \& Aznar Vallejo, 1992).

En el Caribe, las normas jurídicas y los mecanismos administrativos coloniales sufrieron transformaciones. Su conquista y colonización fueron inicialmente manejadas como una empresa comercial, siguiendo los parámetros del modelo de factoría portugués, en este caso administrada por Colón y monopolizada por la Corona, lo que significó una combinación, no pocas veces conflictiva, entre derechos e intereses privados y monárquicos (Deagan, 2002). El abandono de ese modelo mixto y el retorno al monopolio de la Corona (con cambios y ajustes) estuvo en gran medida motivado por las reacciones de una facción de las propias huestes coloniales y de las poblaciones indígenas (Julián, 1997), además, de las necesidades de adaptarse y explotar con rapidez las riquezas en un contexto ecológica y culturalmente diferente. Aspectos que a su vez estimularon la instauración de formas de control y dominación efectivas sobre la población local.

La necesidad de obtener rápidos beneficios modificó el énfasis feudal de instituciones como los repartimientos y las encomiendas, que en el espacio caribeño se transformaron en un medio para la explotación de la mano de obra indígena y congeniar los compromisos de evangelización y las deudas de la Corona con los conquistadores con sus propios intereses económicos (Mira Caballos, 1997, p. 78). A través de las encomiendas, los indígenas fueron utilizados en el desarrollo de actividades económicas relacionadas con modos de producción y hábitos culturales europeos. Actividades como la minería, ganadería, o la agricultura extensiva con fines comerciales propiciaron la transformación de sus prácticas y costumbre tradicionales $\mathrm{y}$, a su vez, generaron una modificación intensa de los paisajes caribeños (Castilla Beltrán et al., 2018; Hooghiemstra et al., 2018; Moreno del Río, 2012).

La evangelización también fue un elemento esencial dentro del proceso colonial del Caribe, sin embargo, los pretextos de superioridad cultural o civilizatoria basados en aspectos religiosos y utilizados durante la reconquista española también debieron ser modificados, especialmente por la ausencia de una tradición literaria o de revelación como entre los llamados "infieles". Esto hizo necesario la transición hacia estrategias que congeniaran evangelización y explotación, como es el caso de la encomienda, y través de ellas, la evangelización tomó diversos caminos y variantes relacionadas con condiciones y reacciones de las poblaciones indígenas y las propias experiencias e intereses hispanos.

En general, la adaptación y transformación cultural de los europeos y de Europa fue un rasgo vinculado con los procesos de colonización del Caribe (Mira Caballos, 2013), aunque lo predominante en los discursos históricos ha sido la exaltación de la aculturación o desaparición de las comunidades indígenas. Enfoque, en el que la colonización del Caribe, generalmente, es percibida como un acontecimiento único y marcador de una división histórica que no toma en consideración sus profundas variaciones en tiempos y lugares.

Particularmente, en el Caribe, se ensayaron y desarrollaron las estrategias de conquista y colonización que fueron esenciales para el control sobre el resto del continente americano, y aunque el universo indígena caribeño fue el punto inicial de contacto entre Europa y las Américas, este se volvió en gran medida invisible en las narrativas coloniales. Esas narrativas, básicamente reflejaron al Caribe como espacio de conflictos geopolíticos entre potencias coloniales (Roca Barea, 2016), o como espacio de desarrollo de las plantaciones y de impulso de la trata de esclavos africanos (Moya Pons, 2008). La marginación de sus pueblos indígenas frente a las grandes civilizaciones 
mayas, aztecas e incas, y la fuerte división de su arqueología e historia en pre-colonial y colonial, también han eclipsado el rol de los primeros pobladores de la región en los procesos de colonización. Además, han llevado al escaso reconocimiento o desconocimiento de sus legados.

\section{El proyecto NEXUS 1492}

Actualmente, el Caribe presenta un paisaje geopolítico diverso en el que su población y su patrimonio están amenazados por los impactos naturales y humanos. Las islas, suelen estar en el centro del debate sobre vulnerabilidad, ya que las tendencias climáticas predicen aumentos en los niveles del mar $y$ en la frecuencia de tormentas y huracanes, lo que evidentemente plantea importantes problemas a las comunidades locales y al patrimonio arqueológico (Cooper \& Peros, 2010; Crock \& Petersen, 1999; Hoogland, Hofman, Hooghiemstra \& Field, 2015; 2016; Rivera Collazo, 2019; Cone et al., 2013). El desarrollo turístico, la construcción de hoteles y campos de golf $\mathrm{u}$ otros proyectos de desarrollo están destruyendo total o parcialmente muchos sitios arqueológicos, en muchos casos, no registrados o documentados (Haviser \& Hofman, 2015; Hofman \& Hoogland, 2016; Siegel et al., 2013).

Fundamentados en las experiencias de varios ańos de investigación y colaboración en el Caribe, se organizó el proyecto NEXUS 1492 financiado por el Consejo Científico de la Unión Europea (ERC), con el objetivo de contrarrestar las visiones sesgadas de la historia caribeña, y abordar los impactos coloniales en la explotación y transformación de sus culturas y sociedades indígenas a escala regional y local. Además, de contribuir a incrementar la conciencia histórica y la protección y salvaguarda del patrimonio material e inmaterial, y al registro de las tradiciones y legados culturales indígenas actualmente vigentes (Hofman, Davies, Brandes \& Willems et al., 2012). El proyecto reunió investigadores de diferentes partes del mundo (muchos de ellos del Caribe), comunidades locales, institutos, organi- zaciones gubernamentales y no-gubernamentales, para abordar sus principales temas desde un marco conceptual único. La colaboración, el intercambio de conocimientos, la contribución al debate social sobre descolonización, interculturalidad, inclusión, cohesión social y formación de la identidad fueron aspectos centrales.

NEXUS 1492, adoptó un diseño de investigación transdisciplinaria utilizando técnicas de vanguardia y desarrollando nuevas herramientas analíticas. En un sentido amplio se ha concentrado en las transformaciones de la cultura y la sociedad y, específicamente, en los paisajes (e.g. Castilla Béltran et al., 2018; Hooghiemstra et al., 2018; Herrera Malatesta, 2018; Jean, 2019; Sonnemann Ulloa Hung \& Hofman, 2016; Ulloa Hung \& Herrera Malaesta, 2015), la salud, la alimentación, las prácticas funerarias (e.g. Ciofalo Sinelli \& Hofman, 2019; Hoogland \& Weston en prep.; Mickleburgh et al., 2019; Weston \& Valcárcel Rojas, 2016), la migración (e.g. Laffoon \& Leppard, 2019; Schroeder et al., 2018), la movilidad e intercambio de los repertorios de cultura material (e.g. Antczak, Antczak, Antczak \& Buffet, 2019; Borck et al. en prep.; Hofman et al. en prep.), la continuidad y persistencia cultural, así como la legislación, la gestión del patrimonio y la educación (e.g. Álvarez en prep.; Ariese, 2018; Byer en prep.; Con Aguilar, 2019; Françoso \& Strecker, 2017; Pesoutová, 2019; Castillo \& Strecker, 2017).

\section{Objetivos}

Uno de sus objetivos metodológicos fue el desarrollo y combinación de herramientas analíticas y metodológicas, por ejemplo: 1) el desarrollo de un dispositivo portátil de ablación láser "no invasivo" para determinar la proveniencia isotópica de la jadeíta caribeña, las piedras semipreciosas y los objetos de oro (Knaf, Koornneef \& Davies et al., 2017); 2) la combinación sistemática de los análisis osteológicos, multi-isotópicos, genéticos, microbiológicos orales, y de análisis de granos de 
almidón y fitolitos, en grandes conjuntos de datos macro-regionales caribeños, para estudiar el origen, la movilidad, las enfermedades, la salud, los patrones dietéticos y sus transformaciones (e.g. Ciofalo et al., 2018; Laffoon, Plomp, Davies, Hoogland \& Hofman, 2015; Pagán Jiménez, 2013; Schroeder et al., 2018; Ziesemer et al., 2015); 3) las investigaciones arqueotanatológicas y forenses de carácter tafonómico para verificar datos observados arqueológicamente sobre descomposición y desarticulación de los huesos humanos en diversos tipos de entierros, lo que proporcionó datos relevantes para reconstruir las transformaciones en las prácticas funerarias indígenas (Hoogland \& Hofman, 2013; Mickleburgh \& Wescott, 2018). Aspectos esenciales del proyecto han sido el involucrar entidades locales y comunidades indígenas en todas las etapas de sus investigaciones; implementar una arqueología comunitaria y una práctica arqueológica descolonizadora a través del intercambio de conocimientos, programas educativos (e.g. Con Aguilar, 2019; Stancioff, 2018) y divulgación pública, entre los que resaltan, la organización de varios seminarios académicos (Ulloa Hung \& Valcárcel Rojas, 2016; 2018), la exposición Lazos Caribeños, inaugurada en la sede del Centro Cultural Eduardo León Jimenes de República Dominicana y de manera paralela en varios países del Caribe, y el documental El retumbar del Caribe indígena producido por Pablo Lozano a partir de la colaboración científica y académica con el Instituto Tecnológico de Santo Domingo (INTEC).

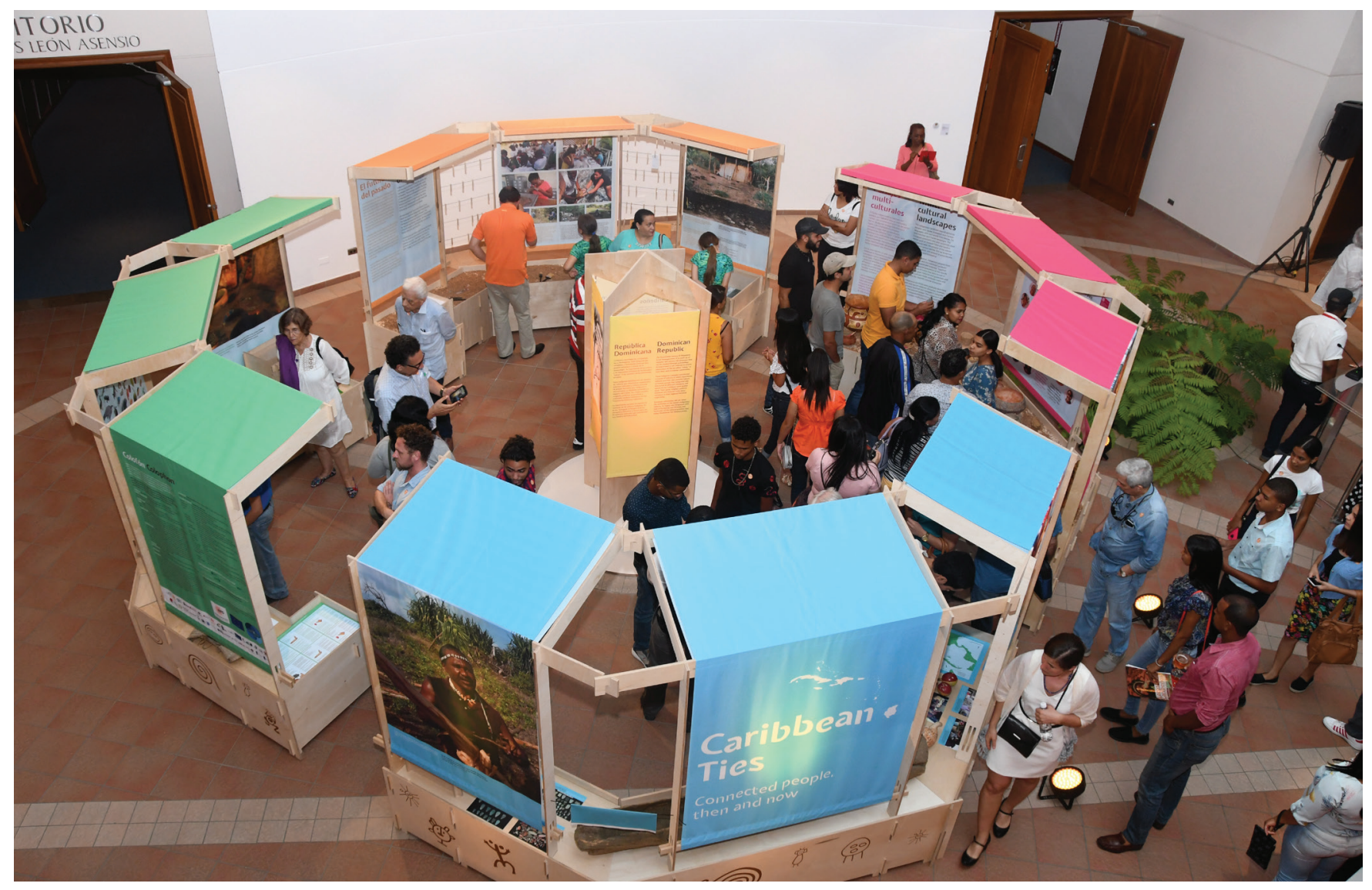

Figura 1. Inauguración de la exposición Lazos Caribeños en la sede del Centro Cultural Eduardo León Jimenes. República Dominicana.

Foto: cortesía del Centro Cultural Eduardo León Jimenes. 


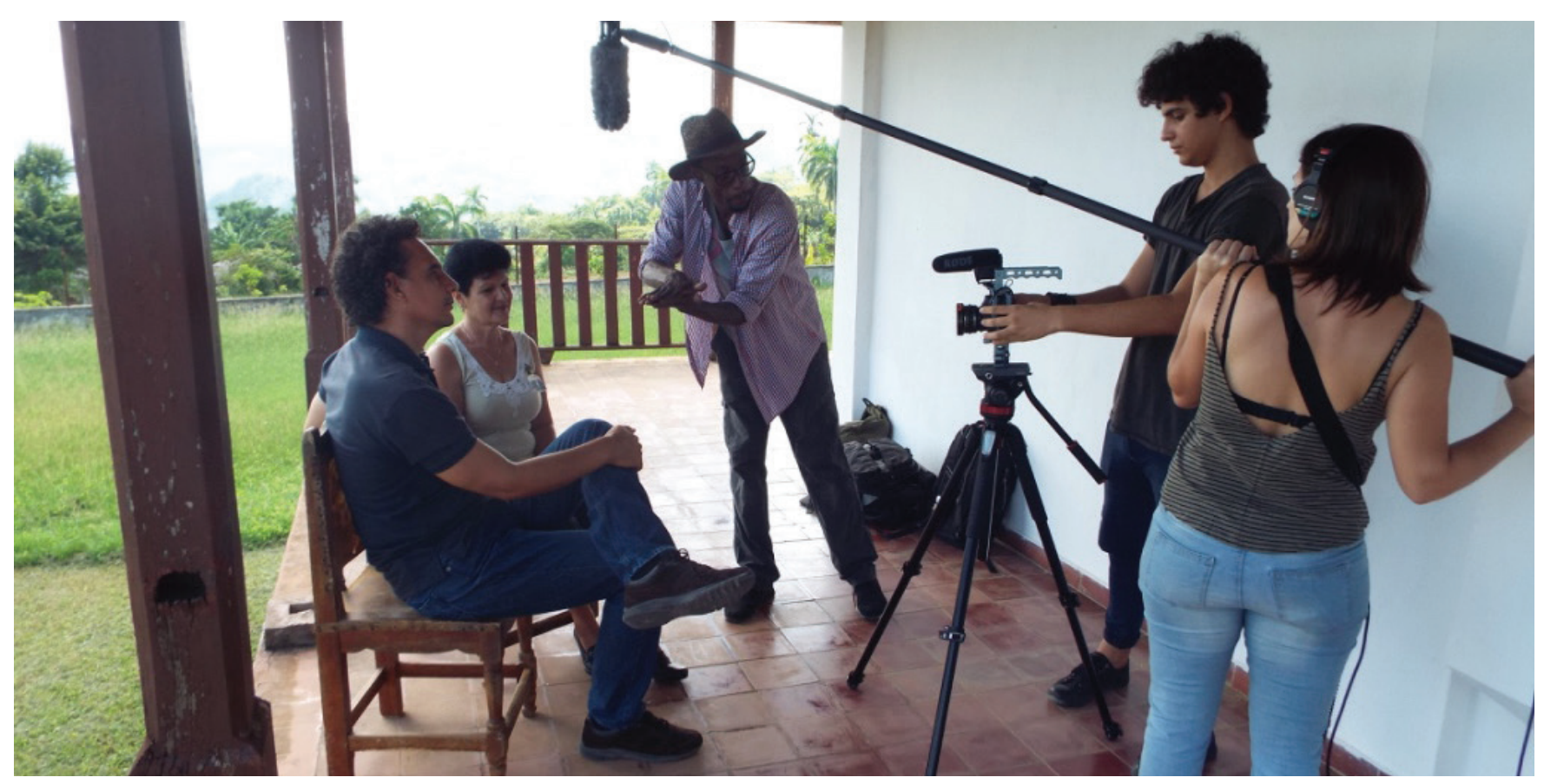

Figura 2. Proceso de grabación de entrevistas y recopilación de datos para el documental. El retumbar del Caribe Indígena. Museo de sitio El Chorro de Maita, Cuba.

Foto: Jorge Ulloa Hung

\section{Reflejos arqueológicos de los procesos de coloni- zación}

Los estudios arqueológicos de caso dentro de NEXUS 1492, abordaron los procesos de colonización entre AD 1492-1800 desde la perspectiva indígena. Un aspecto importante en ese sentido fue tomar en consideración que la colonización europea del Caribe no fue un acontecimiento único, sino un conjunto de procesos dentro de las islas y entre ellas. La mayoría de las áreas alrededor del Mar Caribe fueron colonizadas por los españoles durante el siglo XVI, pero su falta de interés y subsecuentes fracasos en las Antillas Menores las mantuvieron fuera de su control hasta el siglo XVII e incluso el XVIII. Esas diferencias temporales también fueron influenciadas, o determinadas, por la geopolítica europea, los flujos de conquista y colonización hacia Norte, Centro y Sudamérica, las respuestas de las poblaciones indígenas, así como los recursos a explotar en cada isla.

Los casos de estudio arqueológico abordados por el proyecto son ilustrativos de las interacciones y diná- micas interculturales que tuvieron lugar a lo largo del tiempo en diferentes espacios, y se concentraron en las respuestas indígenas a un entorno social y político cambiante.

A continuación, ofreceremos un panorama general de los episodios y regiones en los cuales el proyecto NEXUS 1492 concentró sus principales esfuerzos de investigación arqueológica. En primer lugar, el norte y sureste de La Española, región donde se realizaron las primeras incursiones coloniales en el interior del continente americano. Luego, exploraremos la translocación masiva de pueblos indígenas como esclavos a través del Mar Caribe en relación con la explotación de oro, perlas, y otras riquezas, que comenzaron con el segundo viaje de Colón y se ampliaron durante su tercer viaje. Posteriormente, examinaremos el sistema de encomiendas de principios del siglo xvi en el noreste de Cuba, que ilustra el trabajo forzado y cómo la imposición/ adopción del sistema de creencias cristianas afectó la vida y transformó las prácticas funerarias y la cultura material asociada. Por último, nos referiremos 
el caso de los kalinago de las Antillas Menores y la formación de una nueva identidad, y su persistencia a través de la resistencia y reacción a la invasión colonial en la región.

\section{El Norte de La Española: espacio del primer contacto}

El Norte de La Española fue la primera zona de América donde se produjeron diversas interacciones y extensos enfrentamientos entre pueblos indígenas y europeos. Fue, donde los espańoles entraron por primera vez en el interior de la isla en 1494, aprovechando las redes, el conocimiento y los senderos indígenas. Fue, además, donde los españoles adquirieron nueva información sobre la alimentación, el ambiente y el funcionamiento de las sociedades indígenas, que sería clave para su expansión al resto del arco antillano y del continente. En esta región también, básicamente, emergió su justificación política y cultural para someter a los indígenas al trabajo y la esclavitud (CorcoranTadd, Ulloa Hung, prensa; Hofman et al., 2018). Estudios arqueológicos realizados por los investigadores Jorge Ulloa Hung, Eduardo Herrera Malatesta y Joseph Sony Jean, entre los espacios donde estuvieron enclavadas La Navidad y La Isabela, los primeros lugares españoles en el norte de la isla, registraron más de 300 sitios indígenas (Herrera Malatesta, 2018; Jean, 2019; Ulloa Hung, 2014, Ulloa Hung y Herrera Malatesta, 2015). Estos sitios van desde el período precolonial tardío hasta el período colonial temprano. Nuestras investigaciones (Hofman, Hoogland, Samson \& Oliver,2008; Samson, 2010) en el asentamiento El Cabo San Rafael (2005-2008), complementaron esos datos con evidencias de la interacción indígena-europea en el Sudeste de la isla en un contexto fechado a c. 1502 .

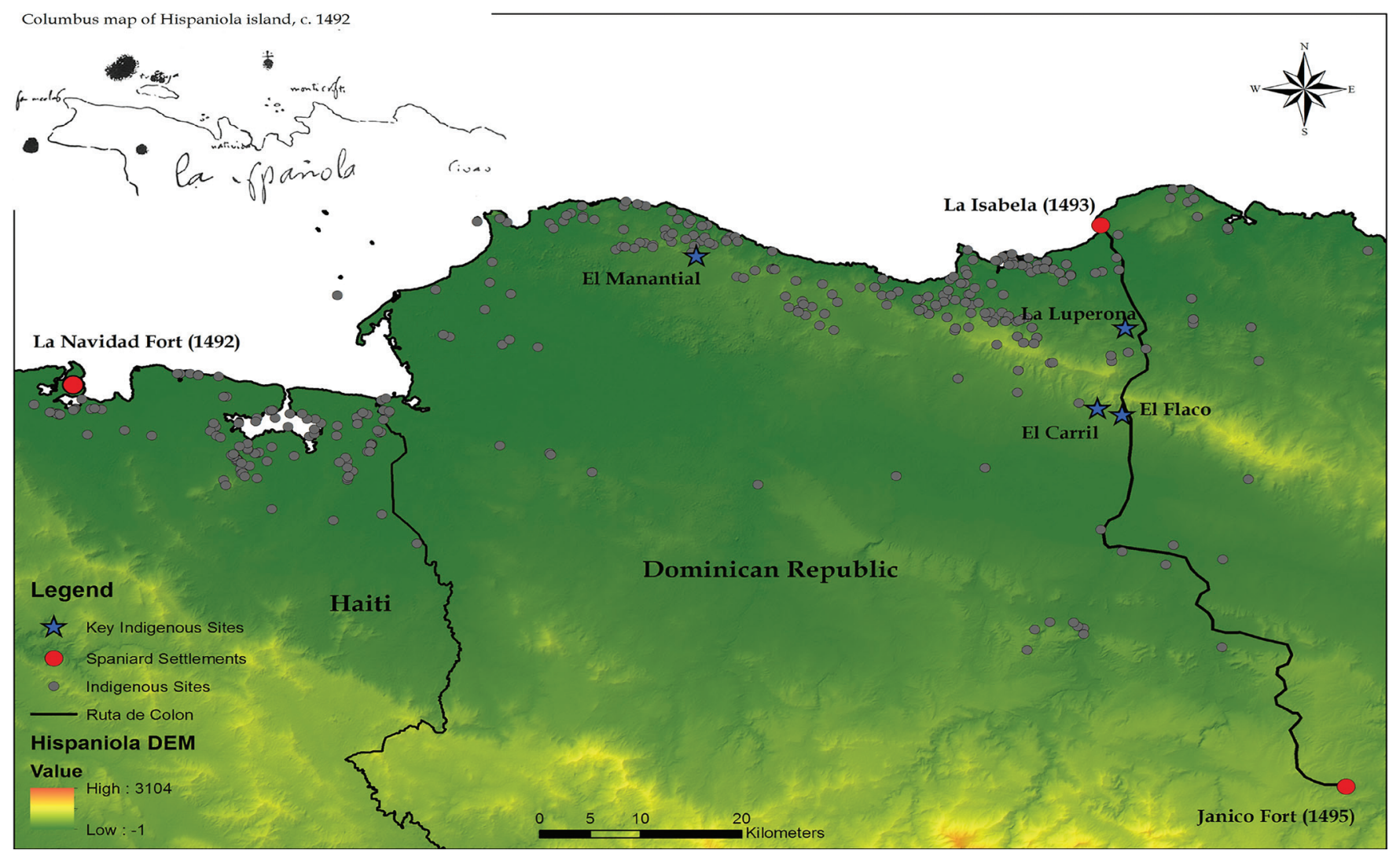

Figura 3. Mapa que ilustra la dispersión de asentamientos arqueológicos indígenas localizados por el proyecto NEXUS 1492 en el entorno de la ruta de Colón y el norte de La Española.

Fuente: mapa elaborado por Eduardo Herrera Malatesta. 
Investigaciones en el área de la Ruta de Colón, la primera ruta colonial desde La Isabela hasta el Valle del Cibao en el centro de la isla, revelaron la existencia de un paisaje cultural diverso caracterizado por el uso de abrigos rocosos o cuevas, asentamientos en espacios abiertos ubicados en la cima de montańas y mesetas de importantes sistemas montañosos, como la Cordillera Septentrional y Central, y a lo largo de los principales sistemas fluviales (Ulloa Hung \& Herrera Malatesta, 2015; Ulloa Hung, 2014). La investigación en esta región se basó en continuar el trabajo de los pioneros de la arqueología dominicana Emile Boyrie Moya, Marcio Veloz Maggiolo, Bernardo Vega, José Guerrero, Elpidio Ortega, Fernando Luna Calderón y Glenis
Tavares, entre otros, quienes trabajaron el área en los ańos ochenta y noventa (Boyrie Moya, 1960; Guerrero \& Veloz Maggiolo, 1988; Veloz Maggiolo, Ortega \& Caba Fuentes, 1981; Veloz Maggiolo \& Ortega, 1980; Vega, 1990).

Los sitios registrados representan solo una pequeña parte de los asentamientos que existían, debido a las enormes transformaciones del terreno generadas a partir de la colonización. Desde sus inicios, la introducción de ganado y diversos cultivos cambiaron drásticamente el paisaje (Castilla Beltrán, 2018; Hooghiemstra et al., 2018). Además, el reciente e intenso cultivo de arroz y plátanos en la zona borró aún más la historia de los asentamientos indígenas.

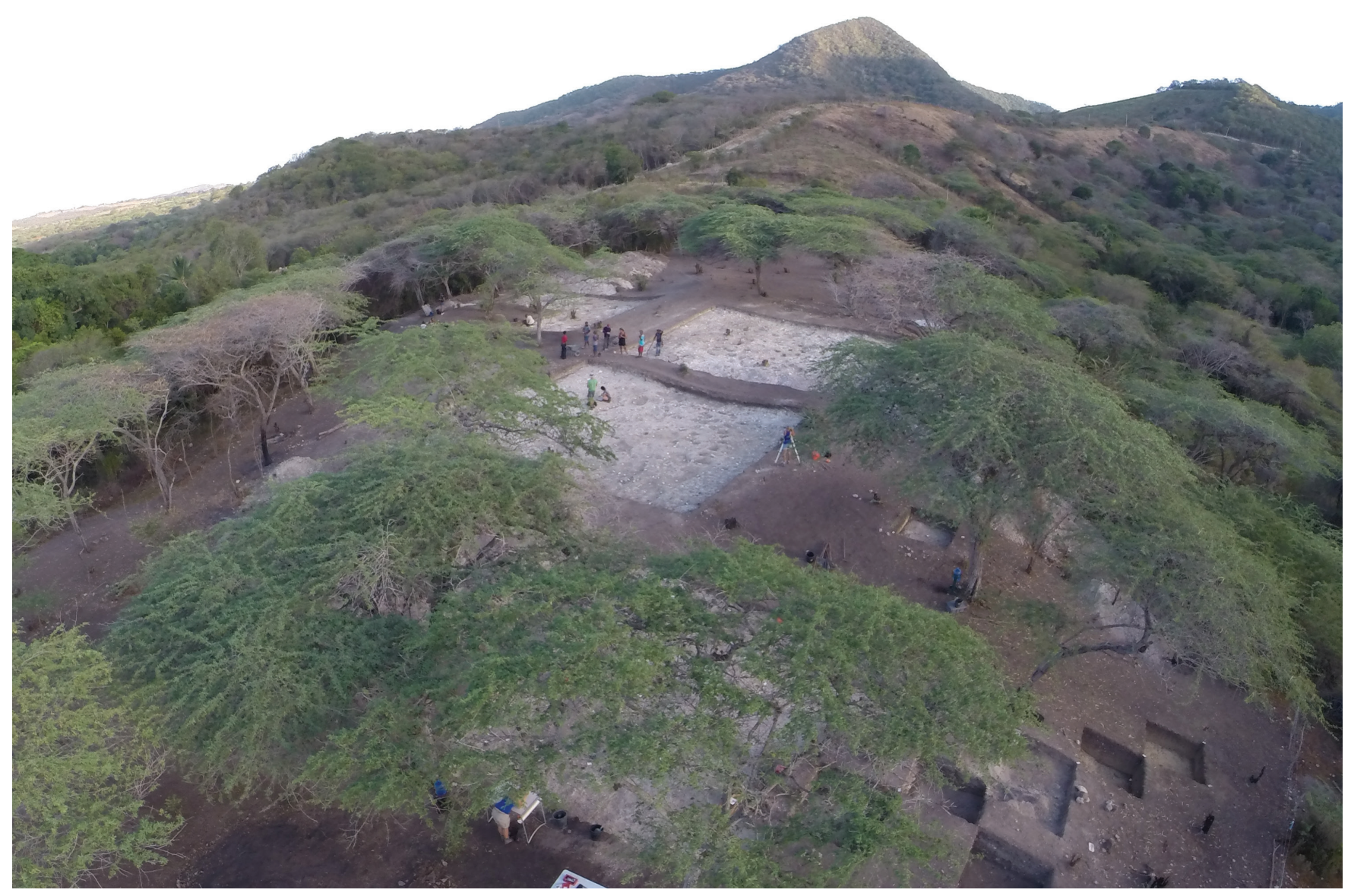

Figura 4. Excavaciones extensas en el asentamiento El Flaco cercano al llamado Paso de Los Hidalgos en la llamada Ruta de Colón.

Fuente: foto tomada con Dron por Till Sonnemann 
Las excavaciones extensas en los pocos asentamientos conservados al pie de la Cordillera Septentrional y cercanos al llamado Paso de los Hidalgos y el Mirador de Colón, lugar por donde Colón cruzó por primera vez la Cordillera Septentrional y observó el Valle del Oro (Cibao), permiten discernir un patrón con montículos y áreas aplanadas para construir casas que es característico en aproximadamente el $30 \%$ de los asentamientos localizados en la región. La compleja estratigrafía de los montículos en los sitios de El Flaco y El Carril con enterramientos humanos y de perros y los numerosos huecos de postes en las áreas aplanadas han revelado que los indígenas manejaron así su paisaje y crearon su espacio de habitación nivelando áreas para construir las casas (Hofman y Hoogland, 2015; Hofman et al., 2018). El suelo de las zonas niveladas fue barrido, y junto a basura acumulada por las actividades domésticas, de cultivo y rituales, se crearon montículos junto a las casas. Estos montículos podían alcanzar 2 metros de altura y 12 metros de diámetro. Los montículos fueron multifuncionales y estuvieron conectados entre sí por terraplenes alargados que rodeaban el área de habitación y marcaban sus lugares ancestrales.

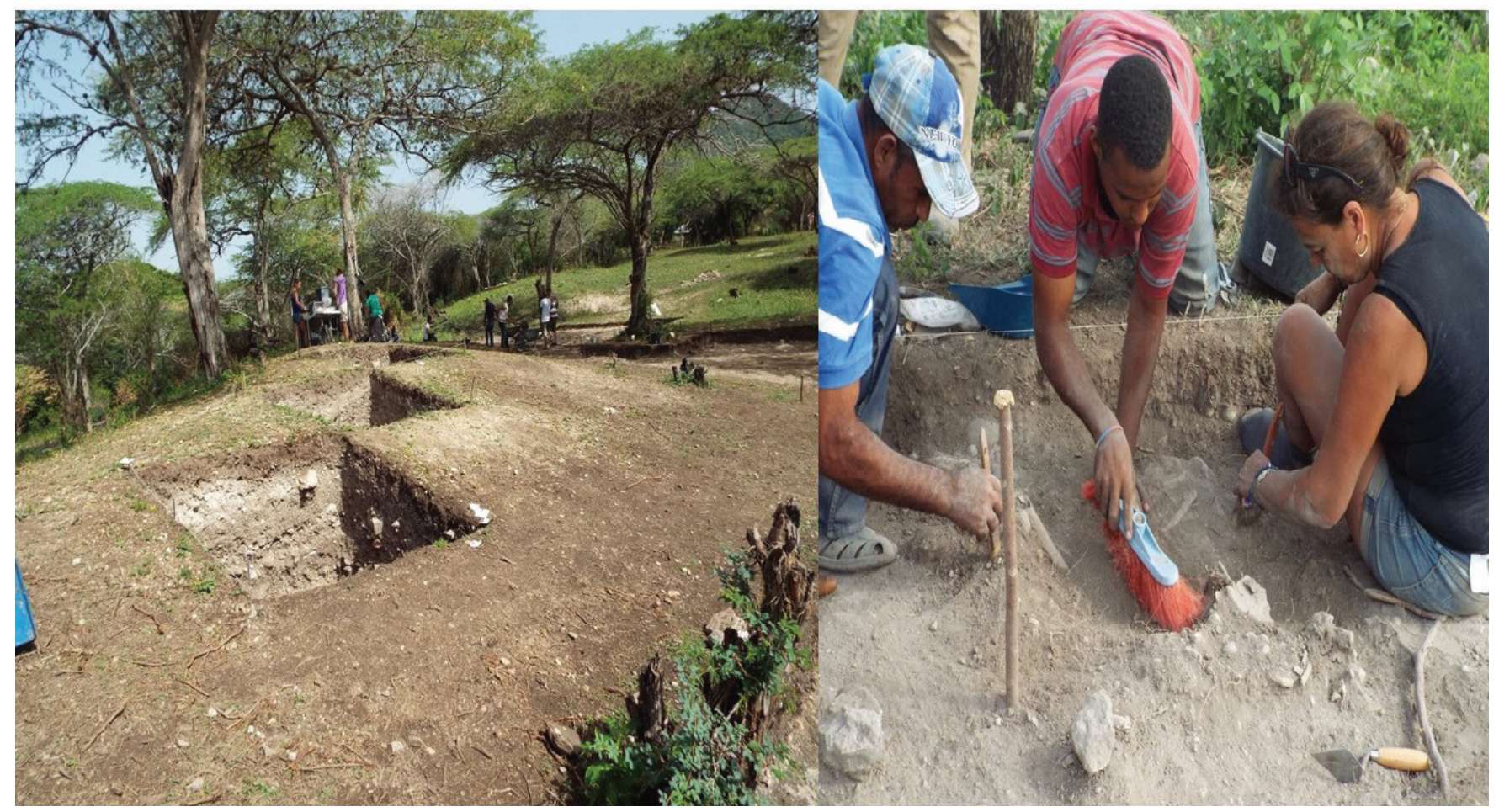

Figura 5. Excavaciones en uno de los montículos del sitio El Flaco (izquierda). La Dra. Corinne L. Hofman junto a los miembros voluntarios de la comunidad Leory Torres y Sonny Torres durante las excavaciones de uno de los enterramientos del sitio El Flaco (derecha).

Fotos: Jorge Ulloa Hung 
La cultura material exhumada, muestra la larga historia de algunos de estos asentamientos. La mezcla de estilos (ejemplo: de las series cerámicas Chicoide/ técnica Meillacoide/motivos y viceversa) alude a una diversidad social y cultural, así como a la existencia de importantes redes sociales (ejemplo: la distribución de jadeíta del área de Río San Juan) en la región, que fue experimentada por los europeos al momento del contacto. Sin embargo, sus descripciones también contribuyeron a minimizar esa diversidad a unas pocas etiquetas, en la que básicamente sobresale la reconocida como cultura 'taína', aspecto que esencialmente se fundamenta en una interpretación errónea y en una construcción conceptual del siglo XIX, que luego fueron utilizadas por los arqueólogos en el siglo xx y aún en la actualidad (Curet, 2014; Keegan \& Hofman, 2017).

Aunque en los asentamientos investigados los materiales europeos están ausentes, y hasta el momento se limitan solo al hallazgo de una punta de metal (Hofman et al., 2018, fig.7), en otros sitios indígenas del periodo de contacto en La Española se han recuperado cuentas de cristal europeas, cascabeles, cuencos rotos, objetos y fragmentos de metal. Estos, junto a camisas, telas de colores y otros objetos reportados por los cronistas, fueron intercambiados por adornos de oro, alimentos, algodón o aves exóticas (García Arévalo, 2003; Keehnen, 2019; López Belando, 2012; Mol, 2011). En el sitio El Cabo San Rafael, en el sudeste de la isla, restos de objetos de factura europea aparecen en áreas claramente segregadas y junto a una parafernalia indígena, lo que sugiere su integración como objetos de prestigio (Samson, 2010). En otras ubicaciones se han encontrado huesos de cerdo y restos de ratas europeas en cantidades considerables, lo que probablemente indica que algunos animales domésticos, en particular el cerdo, fueron rápidamente convertidos en parte de la cocina indígena (Deagan, 2004). Este último, también se convirtió en un importante medio económico y comercial, y sustentó parte de la alimentación en las encomiendas (Pérez Iglesias \& Valcárcel Rojas, 2015; Valcárcel Rojas, 2016), además, junto a otros productos indígenas, se convirtió en un medio logístico para las nuevas expediciones colonizadoras hacia el resto del continente americano.

\section{A la búsqueda de oro y perlas}

Entre los primeros y más importantes centros de trabajo esclavo amerindio se encuentran la industria minera de oro, localizada en Concepción de la Vega (Kulstad, 2008) y Cotuí (Olsen, Bogaert, Duval \& Coste, 2011), y la ciudad española de Nueva Cádiz de Cubagua, espacio de extracción de perlas localizado en las costas de Venezuela. La monumentalidad arquitectónica lograda en esos asentamientos demuestra el poder económico alcanzado a través de la explotación intensa de mano de obra indígena y africana esclavizada (Deagan, 2003; Kulstad, 2019). Durante el tercer y cuarto viaje de Colón (1498-1502), se realizaron las primeras expediciones a la llamada Costa de las Perlas en el norte de Venezuela (Antczak et al., 2019). Necesitados de mano de obra para explotar las minas de oro en La Espańola y las pesquerías de perlas en Cubagua, los españoles iniciaron un movimiento masivo de poblaciones indígenas a través del Caribe y de áreas continentales aledańas (Valcárcel Rojas, 2019). El resultado fue un tráfico de poblaciones indígenas, e incluso su exportación a Europa, lo que además de generar su transformación, propició la aparición de nuevas identidades sociales y culturales a través de la mezcla de poblaciones indígenas de diferentes lugares con poblaciones africanas y europeas. 


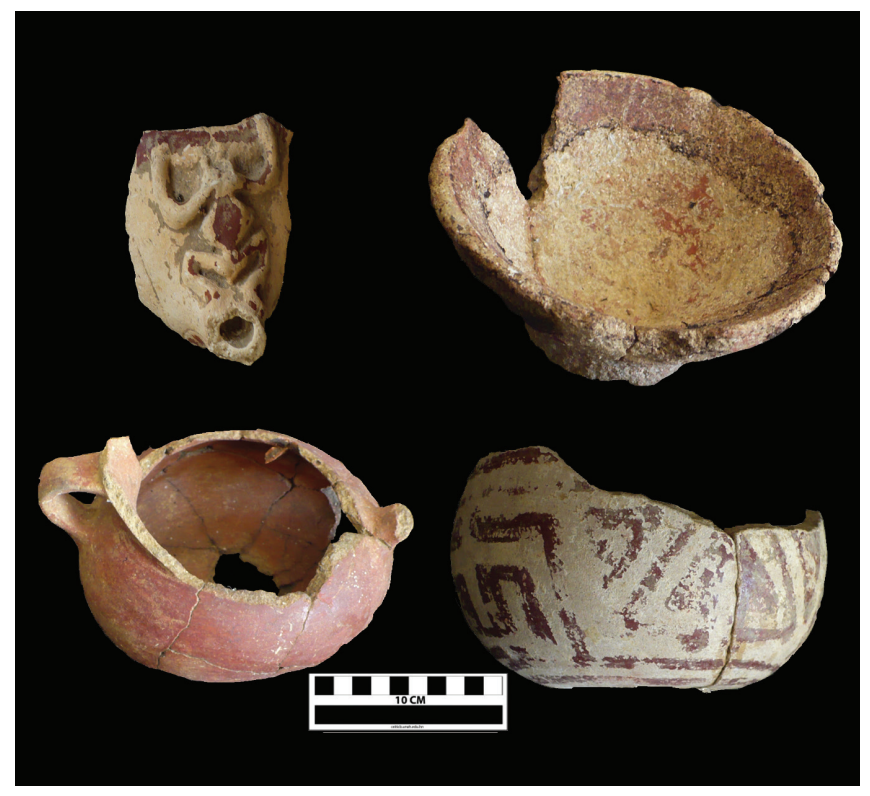

Figura 6. Vasijas con atributos de tradición indígena de la antigua villa espańola de Concepción de La Vega.

Foto: Jorge Ulloa Hung.

En estos lugares, cerámicas indígenas continuaron produciéndose de forma simplificada, y emergieron nuevas formas de vasijas influenciadas por prototipos de América Central, América del Sur, África, y España (Ernst \& Hofman, 2015; 2019; Ortega \& Fondeur, 1978; Ulloa Hung et al., en prensa). La presencia de formas de vasijas españolas realizadas con técnicas indígenas, probablemente refleja la intención de mantener el estilo de vida ibérico en las colonias, aspecto que también se ilustra por la introducción del torno de alfarero. Las vasijas con influencias amerindias y africanas se encuentran básicamente en espacios o áreas de cocina, que fueron de gran importancia para la creación de una temprana sociabilidad transcultural colonial a partir de los cambios y transformaciones en la dieta y sus incidencias en la adaptación de las cerámicas indígenas y africanas (García Arévalo, 1977). La influencia de África Occidental es aparente en ollas hechas a torno, con decoraciones impresas de líneas muy finas, creadas al arrastrar una herramienta "tipo peine" sobre la superficie (Ernst \& Hofman, 2019).

\section{Un cambio radical. El sistema de encomiendas}

El sistema de encomiendas muestra las transformaciones que tuvieron lugar a principios del siglo XVI, cuando los asentamientos indígenas fueron sometidos a un régimen de dominación por los españoles y sus poblaciones fueron complementadas por esclavos africanos e indígenas no locales. Bajo el control de los colonizadores, poblados como el Chorro de Maíta, en el noreste de Cuba, se vieron obligados a aceptar costumbres y tradiciones cristianas y a proporcionar mano de obra a las empresas coloniales españolas (Valcárcel Rojas, 2016; Weston \& Valcárcel Rojas, 2016). Con el sistema de encomienda, las sociedades y culturas indígenas cambiaron radicalmente, pero también tuvieron la capacidad de (re)negociar ciertos aspectos de sus identidades previas al contacto y de sus prácticas de cultura material. Este, fue uno de los escenarios y una de las estructuras coloniales donde el llamado "indio" comenzó a emerger como una categoría y una forma de identidad colonial (Valcárcel Rojas et al., 2014).

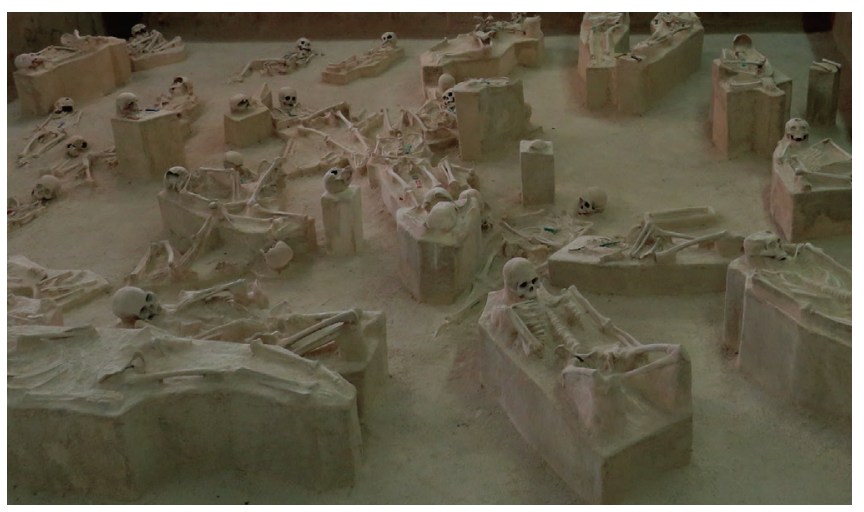

Figura 7. Museo de El Chorro de Maíta, Cuba; vista de reproducciones de restos humanos.

Foto: Roberto Valcárcel Rojas.

En el contexto funerario de Chorro de Maíta, con más de 130 individuos, se percibe una importante evidencia de esta transformación colonial. Los análisis de $\mathrm{ADN}$, el análisis isotópico y el análisis osteológico han identificado además de los indígenas, 
a un individuo de ascendencia africana, posibles mestizos, y un individuo de Yucatán, enterrados en un espacio confinado al centro de la aldea (Valcárcel Rojas, 2016). El perfil demográfico y la estructura del cementerio también indican que enfermedades infecciosas, posiblemente asociadas al contacto europeo, afectaron a la población de El Chorro de Maíta y causaron un aumento de la mortalidad (Weston \& Valcárcel Rojas, 2016). Este aspecto, junto a una disminución en la modificación craneal en los individuos no adultos, refleja cambios significativos en la identidad social (van Duijvenbode, 2017).

Las prácticas funerarias del Chorro de Maíta estudiadas por los investigadores Roberto Valcárcel Rojas y Menno Hoogland muestran la presencia de tradiciones amerindias y europeas; las formas de inhumación del cuerpo flexadas típicas de las prácticas pre-coloniales aparecen junto a la forma cristiana de enterrar a los difuntos en posición estirada con los brazos cruzados sobre el pecho (esta aparece aproximadamente en el $10 \%$ de los entierros incluyendo los de origen indígena) (Valcárcel Rojas, 2016). Agujetas de latón encontradas en varios entierros junto con cierta evidencia tafonómica indican que los individuos probablemente estaban vestidos con ropas europeas; en un entierro se encontró un fragmento de lino europeo. Otros individuos fueron enterrados con una mezcla de guanín (aleación de oro y cobre) adornos de oro de Colombia, y artículos europeos de latón (Cooper et al., 2008; Martinon Torres et al., 2007; Valcárcel Rojas, 2016).

\section{La creación de una identidad kalinago}

Las Antillas Menores, en los siglos XV y XVI, eran conocidas por ser un espacio o reservorio para la búsqueda de esclavos indígenas, pero también funcionaban como refugio para comunidades indígenas de las Antillas Mayores y Sudamérica. Los "caribes de las islas" o kalinago, cuyos orígenes se localizan en el continente sudamericano justo antes de la llegada de Colón, eran considerados feroces y rebeldes por los españoles. La imagen del kalinago, conocida por nosotros a través de los cronistas, es la de comunidades que se resistieron a la expansión y el control espańol creando reductos en las pequeñas islas, pero también sirviendo como "intermediarios" en el comercio entre el Caribe español y América del Sur. Los kalinago estuvieron rodeados de potencias coloniales en expansión, sin embargo, siguieron siendo autónomos y tuvieron la capacidad de renegociar sus nuevas realidades coloniales. A pesar de esto, su existencia y persistencia fue cuestionada durante mucho tiempo por la falta de pruebas arqueológicas (Davis \& Goodwin, 1990; Sued Badillo, 1978; 1992).

La cerámica denominada Cayo ha sido relacionada con los kalinago y es característica de los asentamientos post-contacto (Boomert, 1995; Hofman \& Hoogland, 2018). Hasta ahora se ha encontrado en más de 20 sitios arqueológicos entre las islas de Granada y Guadalupe en las Antillas Menores (Hofman et al., 2010; Keegan \& Hofman, 2017). Además, el repertorio mixto de su cultura material entrelaza formas de vasijas y elementos decorativos locales con los de las Antillas Mayores y el continente. El surgimiento de una nueva identidad kalinago, a través de la formación de un nuevo idioma y la organización de eventos cohesionadores y actividades festivas, explicaría la gran cantidad de objetos y parafernalia suntuaria producto de estos vínculos con las Antillas Mayores y el continente (Hofman, 2019; Hofman et al. en prep.). Recientes análisis (XRF) a esta cerámica revelan su fabricación local y más bien sugieren el movimiento de personas desde esas regiones hacia las islas (Scott, Neyt, Hofman \& Degryse, 2018). Por otro lado, el análisis isotópico de su parafernalia hecha en hueso también evidencia continuas relaciones de intercambio con sus parientes del continente (Laffoon et al. en prep.).

La presencia de mercancías españolas, portuguesas, holandesas, francesas e inglesas en sitios con cerámica 
Cayo referencia la existencia de un patrón comercial entre los kalinago y los europeos (Hofman, 2019). Los kalinago probablemente participaron en un complejo sistema transatlántico en el que se combinaron sus conocimientos sobre intercambio y redes sociales de alianzas con las nuevas estrategias comerciales de las potencias coloniales europeas. Estas comunidades indígenas estaban encapsuladas en los territorios de expansión de estas potencias, sin embargo, disfrutaban de un alto grado de autonomía y tuvieron capacidad para renegociar su situación en esa nueva realidad caracterizada por la nueva afluencia de gentes, bienes e ideas (Hofman et al., 2014).

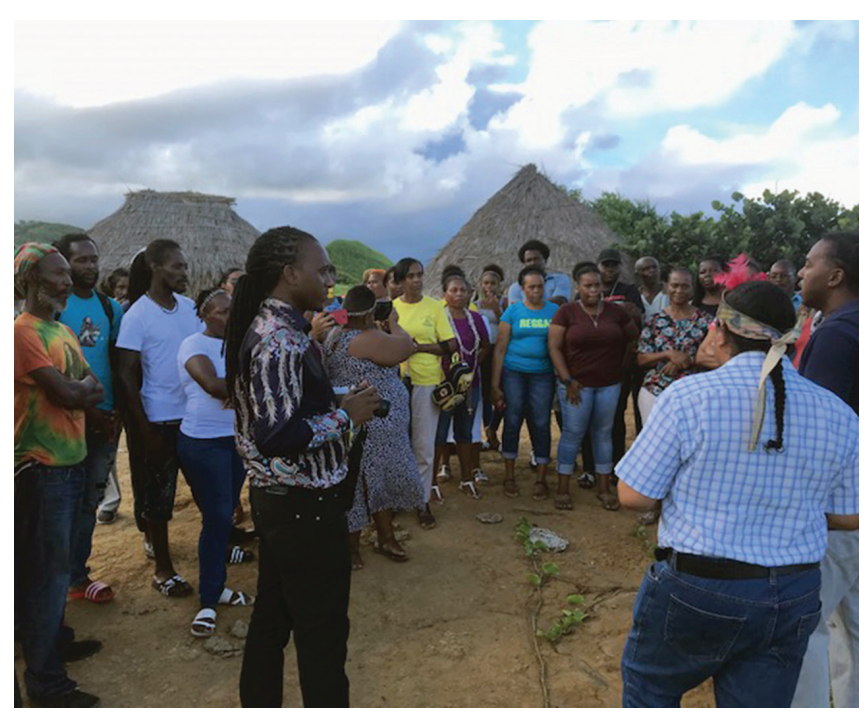

Figura 8. Garífunas y kalinagos visitando el poblado Cayo, construido experimentalmente en la localidad del asentamiento arqueológico de Argyle en San Vincente.

Foto: Corinne L. Hofman.

Algunos ejemplos ilustran esta realidad a partir de la mezcla de elementos indígenas y europeos en un mismo objeto. Esto se evidencia en un fragmento de cerámica indígena en el que fueron incrustadas pequeñas cuentas blancas de semillas europeas, además, en un diente de cerdo perforado de manera similar a los colgantes indígenas confeccionados en dientes de otras especies autóctonas como tapir, pecarí y perro (Hofman et al., 2019).
Los asentamientos de los kalinago están generalmente situados en el lado de barlovento de las islas que dan al Océano Atlántico. En su mayoría están localizados en las islas de Guadalupe (Basse Terre), Dominica, San Vincente y Granada (Boomert, 2011; Bright, 2011; Hofman \& Hoogland, 2012, Hofman et al., 2019). Esta particular ubicación se describe en los primeros documentos europeos, en los que se refiere que los Caribes preferían el lado de barlovento de las islas debido a los escarpados acantilados y lo agitado del mar, lo que contribuía en la defensa de sus asentamientos contra los europeos (Hofman \& Hoogland 2012; Hofman et al., 2015). La excavación del sitio Kalinago del periodo de contacto Argyle en San Vincente con sus numerosos huecos de postes (Hofman \& Hoogland, 2012) nos ha permitido la reconstrucción experimental de esta aldea en 2016 con la participación de las comunidades indígenas (kalinagos y garífunas) de esta isla (Hofman \& Hoogland, 2016; Sankatsing Nava \& Hofman, 2018).

\section{Persistencia y continuidad}

Elementos indígenas han persistido en la cultura material y espiritual de muchos, sino de todos los países del Caribe, y siguen constituyendo parte importante de su vida cotidiana (Hofman et al. en prep; García Molina, Garrido Mazorra \& Fariña Gutiérrez, 2007; Ulloa Hung \& Valcárcel Rojas, 2016a; Valcárcel Rojas \& Ulloa Hung, 2018; Pesoutová, 2019; Pesoutová \& Hofman, 2016; Prieto Vicioso, 2007; Vega, 1981). La continuidad indígena, en las formas de ser y hacer en el Caribe, es visible a través del sentido humano de pertenencia y resiliencia, pero también en la composición genética de sus poblaciones (Moreno Estrada et al., 2013; Schroeder et al., 2018). El intento colonial de borrar los elementos indígenas de las culturas y sociedades del Caribe desde diferentes puntos de vista y a través de los más diversos mecanismos distan mucho de ser completo. Sin embargo, sí contribuyeron a su transformación y en las maneras en que estos se han insertado y perdurado en las sociedades poscoloniales caribeñas. 


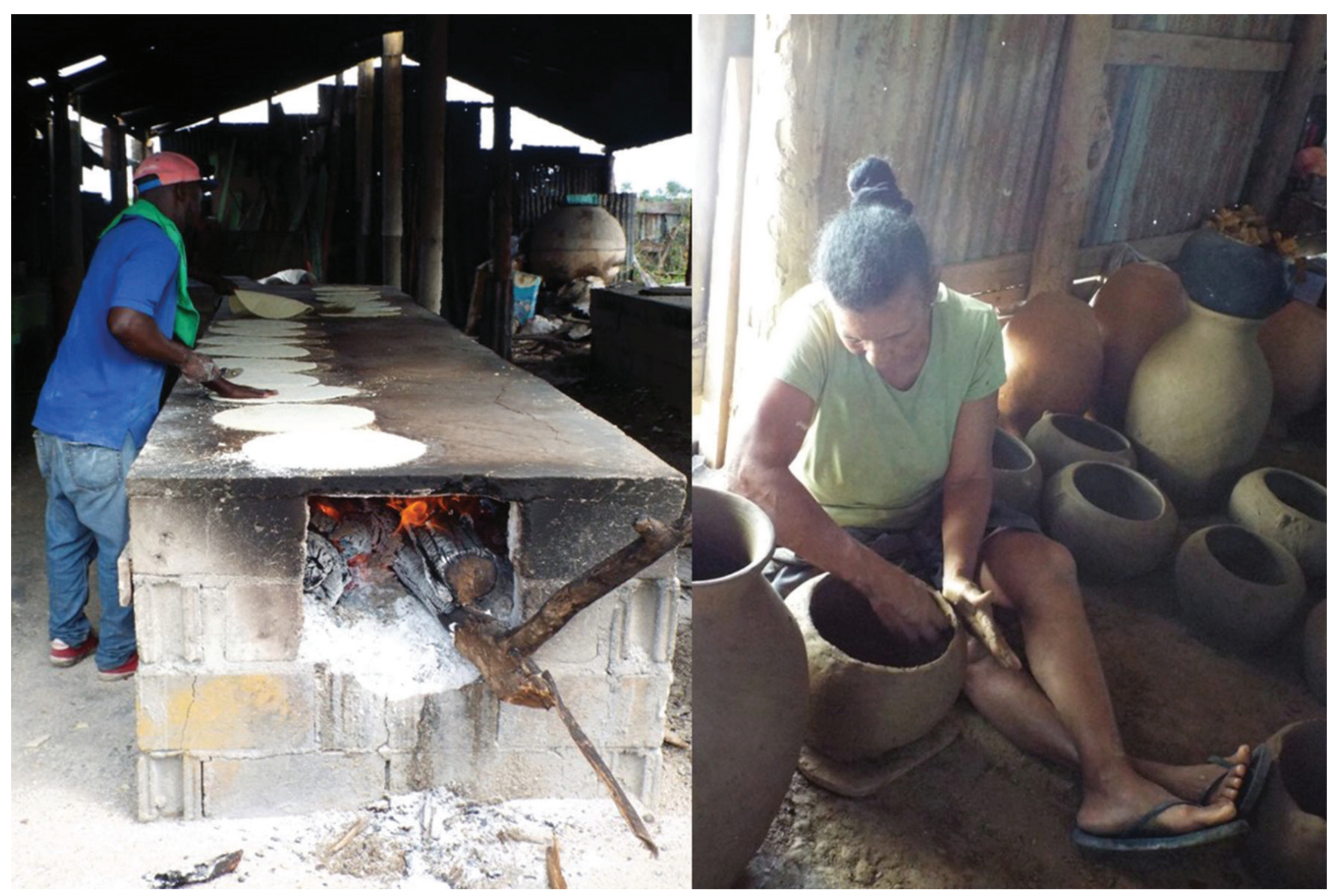

Figura 9. Actividades relacionadas con legados culturales indígenas en la actualidad.

Producción de casabe en San José de Las Matas. Cordillera Central. República Dominicana (izquierda). Confección de ollas y recipientes de cerámica utilizando técnicas tradicionales. Poblado de Higuerito. Valle del Cibao. República Dominicana (derecha).

Fotos: Jorge Ulloa Hung.

Los legados y persistencias del universo cultural indígena no se desvinculan de las relaciones interculturales y mestizajes que tuvieron lugar en variados contextos del Caribe. En zonas rurales, minas, caseríos, ingenios, hatos, haciendas ganaderas, y también en los llamados pueblos de indios o en espacios urbanos de villas y ciudades relacionadas con el mundo colonial caribeño (Roura, 2018; Reyes Cardero, 2018), emergieron nuevas formas culturales e identidades bajo importantes influencias indígenas, españolas y africanas, pero también se desarrollaron y persistieron prácticas económicas y de vida cotidiana donde la cultura material y los saberes indígenas fueron vitales.

Esa persistencia de tradiciones y saberes indígenas a lo largo del período colonial y hasta nuestros días contradice fuertemente la idea de sustitución, desplazamiento o desaparición, como lo sugieren los criterios históricos tradicionales. También, conecta a los pueblos del Caribe con una historia que desde sus inicios es mucho más diversa y compleja que la reflejada por las narrativas basadas en los primeros documentos coloniales.

A través de todo el arsenal de investigación y divulgación científica, el proyecto NEXUS 1492 ha intentado crear conciencia sobre la historia y el patrimonio de los pueblos indígenas, quienes no solo 
fueron los primeros pobladores del Caribe, sino que también han impactado enormemente en la creación de una sociedad multicultural y multiétnica en cada isla y en el Caribe en general. Su historia severamente descuidada y subestimada merece ahora más que nunca ser revisada y convertirse en una parte crucial en los currículos educativos regionales y en el discurso global.

\section{Agradecimientos}

La investigación que condujo a estos resultados ha recibido financiación del Consejo Europeo de Investigación en virtud del Séptimo Programa Marco de la Unión Europea (FP7 / 2007-2013) / ERC-NEXUS1492 acuerdo de subvención 319209, dirigido por la Profesora Dra. Corinne L. Hofman. Agradecemos al Ministerio de Cultura de la República Dominicana, al Museo del Hombre Dominicano y la Dirección de Patrimonio Monumental por conceder permisos para nuestra investigación. Además, al Instituto Tecnológico de Santo Domingo (INTEC) y al Centro Cultural Eduardo León Jimenes por su colaboración Académica y Científica en este proyecto. Estamos particularmente agradecidos con los propietarios de tierras, las comunidades, voluntarios locales y todas las instituciones del Caribe por colaborar en las investigaciones y compartir con nosotros sus valiosos conocimientos.

\section{Referencias}

Álvarez, A. (en prep.). From enclosed spaces to community surroundings: Indigenous heritage collections in the Dominican Republic (Doctoral dissertation). Leiden University, Leiden, The Netherlands.

Antczak, A. T., Antczak, M. M., Antczak, O., \& Buffet, L. A. L. (2019). Rancherías: Historical Archaeology of Early Colonial Campsites on Margarita and Coche Islands, Venezuela. In Material Encounters and Indigenous Transformations in the Early Colonial Americas (pp. 146-174). Leiden, Holanda: Brill.
Ariese, C. E. (2018). The social museum in the Caribbean: grassroots heritage initiatives and community engagement (doctoral dissertation). University of Leiden, Leiden: Holanda.

Boomert, A. (1995). Island Carib Archaeology. Wolves from the Sea: Readings in the Anthropology of the Native Caribbean, (pp. 23-36). Leiden: KITLV Press.

Boomert, A. (2000). Trinidad, Tobago, and the Lower Orinoco interaction sphere: an archaeologicall ethnohistorical study. Cairi Publications.

Boomert, A. (2011). From Cayo to Kalinago. En C.L. Hofman, \& A. van Duijvenbode, (eds.), Communities in contact. Essay in archaeology, ethnohistory and ethnography, (pp. 291-306). Leiden, Holanda: Sidestone press.

Bright, A. J. (2011). Blood is thicker than water: Amerindian intra-and inter-insular relationships and social organization in the pre-Colonial Windward Islands. Leiden, Holanda: Sidestone Press.

Borck, L.S., Davies, G.R., Brandes, U., Ulloa Hung, J., Valcárcel Rojas, R., \& Hofman, C.L. en prep. Networks and social transformations. In C.L. Hofman, J. Ulloa Hung, G.R. Davies, \& U. Brandes (Eds.), NEXUS1492: New World Encounters in a Globalizing World. Leiden: Brill.

Boyrie Moya, E. (1960). Cinco años de arqueología Dominicana. Anales de la Universidad de Santo Domingo Vol. 26, p 33-86. Santo Domingo, República Dominicana: Universidad de Santo Domingo.

Byer, A. (en prep.). The Role of Law in the Protection of Archaeological Heritage in the Lesser Antilles: A Critical and Comparative Analysis (Doctoral dissertation). Leiden University, Leiden, The Netherlands.

Castilla Beltrán, A, Hooghiemstra, H., Hoogland, M.L, Pagán Jiménez, J., van Geel, B., Field, M.H, Prinsc, M., Dondersd, T.; Herrera Malatesta, E, Ulloa Hung, J., McMichaela, C.H, Goslinga, W.D, Hoofman, C.L. (2018). 
Columbus' footprint in Hispaniola: A paleoenvironmental record of indigenous and colonial impacts on the landscape of the central Cibao Valley, northern Dominican Republic. Anthropocene, 22, 66-80. doi: https://doi. org/10.1016/j.ancene.2018.05.003

Castillo, M. M. \& Strecker, A. (Eds.). (2017). Heritage and Rights of Indigenous Peoples. Leiden, Holanda: Leiden University Press.

Ciofalo, A. J., Keegan, W. F., Pateman, M. P., PagánJiménez, J. R. \& Hofman, C. L. (2018). Determining precolonial botanical foodways: starch recovery and analysis, Long Island, The Bahamas. Journal of Archaeological Science: Reports, 21, 305-317.

Ciofalo A.J., Sinelli, P.T. \& Hofman, C.L. (2019). Late Precolonial Culinary Practices: Starch Analysis on Griddles from the Northern Caribbean, Journal of Archaeological Method and Theory, 1-33.

Con Aguilar. E. (2019). Heritage education-Memories of the past in the present Caribbean social studies curriculum: a view from teacher practice (doctoral dissertation). University of Leiden. Leiden, Holanda.

Cone, J., Rowe, S., Borberg, J., Stancioff, E., Doore, B. \& Grant, K. (2013). Reframing engagement methods for climate change adaptation. Coastal Management, 41(4), 345-360.

Cooper, J., Martinon-Torres, M. \& Valcárcel Rojas, R. (2008). Metal Objects and Indigenous Values in the Cemetery of El Chorro de Maíta. C.L. Hofman, M.L. Hoogland, P. Annelou \& L. van Gijn (eds.), Cuba. Crossing the Borders. New Methods and Techeniques in the study of Archaeological material from the Caribbean, (pp. 34-42). Tuscaloosa, Estados Unidos: University of Alabama Press.

Cooper, J. \& Peros, M. (2010). The archaeology of climate change in the Caribbean. Journal of Archaeological Science, (37), 1226-1232.

CorcoranTadd, N., Ulloa Hung, J., Antczak, A., Herrera Malatesta, E. \& Hofman, C.L. (2019). Indigenous Routes and Resources Materialities in the Early Spanish Colonial World; Comparative Archaeological Approaches. En preparación

Crock, J. G. \& Petersen, J. B. (1999). A long and rich cultural heritage: the Anguilla archaeological project, 1992-1998. Report Prepared for the Anguilla Archaeological and Historical Society, The Valley.

Curet, L. A. (2014). The Taíno: Phenomena, concepts, and terms. Ethnohistory, 61(3), 467-495.

Davis, D. D. \& Goodwin, R. C. (1990). Island Carib origins: evidence and non evidence. American Antiquity, 55(1), 37-48.

Deagan, K. (2002). La Isabela y su papel en el paradigma inter-atlántico: la colonia española de la isla Española (1493-1550) desde la perspectiva arqueológica. XV Coloquio de Historia CanarioAmericana, Las Palmas de Gran Canaria, (pp. 1987-1998). Disponible en http://anuariosatlanticos.casadecolon.com/index.php/CHCA/ issue/view/263

Deagan, K. (2003). Colonial origins and colonial transformations in Spanish America. Historical Archaeology, 37(4), 3-13.

Deagan, K. 2004 Reconsidering Taino Social Dynamics After Spanish Conquest: Gender and Class in Culture contact Studies. American Antiquity, 69(4), 597-626.

Duijvenbode, A. V. (2017). Facing society: A study of identity through head shaping practices among the indigenous peoples of the Caribbean in the ceramic age and colonial period, (doctoral dissertation). Leiden University. Leiden, Holanda. Disponible en. https://openaccess.leidenuniv. nl/handle/1887/49749

Ernst, M. \& Hofman. C. L (2015). Shifting Values: A study of early European trade wares in the Amerindian site of El Cabo, eastern Dominican Republic. En J. Buxeda, I Garrigós, M. Madrid, I Fernández \& J.G. Ińañez (eds.). Global Pottery I. Historical Archaeology and Archaeometry for Societies in Contact. (pp.195-204) Oxford, Inglaterra: BAR International Series. 
Ernst, M. \& Hofman, CL. (2019). Breaking and Making Identities: Transformations of Ceramic Repertoires in Early Colonial Hispaniola. En C.L. Hofman \& F.W.M. Keehnen (eds.). Material Encounters and Indigenous Transformations in the Early Colonial Americas: Archaeological Case Studies, (pp. 125-145) Leiden, Holanda: Brill.

Françozo, M. \& Strecker, A. (2017) Caribbean Collections in European Museums and the Question of Returns. International Journal of Cultural Property 24:451-477. DOI: 10.1017/ S0940739117000248.

García Arévalo, M. (1977). Influencias de la dieta indohispánica en la cerámica taína. Séptimo Congreso Internacional para el estudio de las culturas precolombinas de las Antillas Menores, (pp. 263-277). Quebec, Canadá: Centre de Recherches Caraibes.

García Arévalo, M. (2003). Los tainos en los apuntes de Cristóbal Colón. Revista Instituto de Cultura Puertorriqueña, 4(7), 133.

García Molina, J. A., Garrido Mazorra, M. \& Fariña Gutiérrez, D. (2007). Huellas vivas del indocubano. La Habana, Cuba: Editorial de Ciencias Sociales.

Guerrero, J. \& Veloz Maggiolo, M. (1988). Los inicios de la colonización en América. San Pedro de Macorís, República Dominicana: Ediciones de la UCE.

Haviser, J. B. \& Hofman, C. L. (2015). A review of archaeological research in the Dutch Caribbean. Managing our Past into the Future: Archaeological Heritage Management in the Dutch Caribbean, 37-70.

Herrera Malatesta, E. (2018). Una isla, dos mundos: estudio arqueológico sobre el paisaje indígena de Haytí y su transformación al paisaje colonial de La Española (1200-1550). Leiden, Holanda: Sidestone Press.

Hofman, C. L., Hoogland, M. L. P., Samson, A. V. M. \& Oliver, J. R. (2008). Investigaciones arqueológicas en El Cabo, oriente de la República Dominicana: Resultados preliminares de las campañas 2005 y 2006. Boletín del Museo del Hombre Dominicano, 42, 307-316.
Hofman, C. L., Bright, A. J., Ramos, R. R (2010). Crossing the Caribbean Sea: Towards a holistic view of pre-colonial mobility and exchange. Journal of Caribbean Archaeology, 3, 1-18.

Hofman, C.L., Davies, G.R; Brandes, U, \& Willems, W. (2012). Nexus 1492: New World Encounters in a Globalising World. ERC Synergy Grant 2012 Research proposal.

Hofman, C., Mol, A., Hoogland, M. \& Valcárcel Rojas, R. (2014). Stage of encounters: migration, mobility and interaction in the pre-colonial and early colonial Caribbean. World Archaeology, 46(4), 590-609.

Hofman, C. L. \& Hoogland, M. L. (2012). Caribbean encounters: rescue excavations at the early colonial Island Carib site of Argyle, St. Vincent. Analecta Praehistorica Leidensia, 43(44), 63-76.

Hofman, C.L. \& M.L.P. Hoogland. (2015). Investigaciones arqueológicas en los sitios $\mathrm{El}$ Flaco (Loma de Guayacanes) y La Luperona (Unijica): Informe preliminar. Boletín del Museo del Hombre Dominicano, 46(42), 61-74.

Hofman, C. L., Hoogland, M. L. \& Roux, B. (2015). Reconstruire le táboüi, le manna et les pratiques funéraires au village caraïbe d'Argyle, Saint-Vincent. À la recherche du Caraïbe perdu: Les populations amérindiennes des Petites Antilles de l'époque précolombienne à la période coloniale, 41-50.

Hofman, C. L. \& Hoogland, M. L. (2016). Connecting stakeholders: Collaborative preventive archaeology projects at sites affected by natural and/or human impacts. Caribbean Connections, 5(1), 1-31.

Hofman, C. L. \& Hoogland, M. L. (2018). Arqueología y patrimonio de los Kalínago en las islas de San Vincente y Granada. En R. Valcarcel Rojas\& J. Ulloa Hung (eds.) De la desaparición a la permanencia. Indigenas e indios en la reinvención del Caribe, (pp. 227-245). Santo Domingo, República Dominicana: Instituto Tecnológico de Santo Domingo Fundación García Arévalo. 
Hofman, C. L., Ulloa Hung, J., Herrera Malatesta, E., Jean, J. S., Sonnemann, T. \& Hoogland, M. (2018). Indigenous Caribbean perspectives: archaeologies and legacies of the first colonised region in the New World. Antiquity, 92(361), 200-216.

Hofman, C. L. (2019). Indigenous Caribbean Networks in a Globalizing World. Power, Political Economy, and Historical Landscapes of the Modern World: Interdisciplinary Perspectives, 55.

Hofman, C. L., Hoogland, M. L., Boomert, A. \& Martin, J. A. (2019). Colonial Encounters in the Southern Lesser Antilles: Indigenous Resistance, Material Transformations, and Diversity in an Ever-Globalizing World. Material Encounters and Indigenous Transformations in the Early Colonial Americas, (pp. 359-384). Leiden, Holanda: Brill.

Hofman, C.L., Ulloa Hung, J., Brandes, U., Davies, G.R., \& Strecker, A. (en prep). A synergy of stakeholders and disciplines. In C.L. Hofman, J. Ulloa Hung, G.R. Davies, \& U. Brandes (Eds.), NEXUS1492: New World Encounters in a Globalizing World. Leiden: Brill.

Hoogland, M. L. \& Hofman, C. L. (2013). From Corpse Taphonomy to Mortuary Behavior in The Caribbean. The Oxford handbook of Caribbean archaeology, 52, 452.

Hoogland, M. L. P., Hofman, C. L., Hooghiemstra, H., \& Field, M. H. (2015). Under the mangrove: Coastal dynamics and deeply buried deposits at the site of Anse Trabaud, Martinique. XXVI Congress of the International Association for Caribbean Archaeology. St. Martin.

Hoogland, M.L.P., \& Weston, D.A. en prep. The Routledge Handbook of Bioarchaeology in the Caribbean. London: Routledge.

Hooghiemstra, H., Olijhoek, T., Hoogland, M., Prins, M., van Geel, B., Donders, T., Gosling, W \& Hofman, C. L (2018). Columbus' environmental impact in the New World: Land use change in the Yaque River valley, Dominican Republic. Holocene, 28(11), 1818-1835. doi: https://doi. org/10.1177/0959683618788732

Jean, J.S. (2019). La Biographie d'un paysage. Etude sur les transformations de longue durée du paysage culturel de la région de Fort-Liberté, Haïti. Leiden, Holanda: Sidestone Press.

Julián, A. (1997). Bancos, ingenios y esclavos en la época colonial. Santo Domingo, República Dominicana: Banco de Reservas de la República Dominicana.

Keegan, W. F. \& Hofman, C. L. (2017). The Caribbean before Columbus. Oxford, Inglaterra: Oxford University Press.

Keehnen, F. W., Hofman, C. L. \& Antczak, A. T. (2019). Material Encounters and Indigenous Transformations in the Early Colonial Americas. Material Encounters and Indigenous Transformations in the Early Colonial Americas, (pp. 1-31). London, Inglaterra: Brill.

Keehnen, F. W. (2019). Treating 'Trifles': the Indigenous Adoption of European Material Goods in Early Colonial Hispaniola (14921550). Material Encounters and Indigenous Transformations in the Early Colonial Americas, (pp. 58-83). London, Inglaterra: Brill.

Knaf, A. C. S., Koornneef, J. M. \& Davies, G. R. (2017). "Non-invasive" portable laser ablation sampling of art and archaeological materials with subsequent $\mathrm{Sr}-\mathrm{Nd}$ isotope analysis by TIMS using $1013 \Omega$ amplifiers. Journal of Analytical Atomic Spectrometry, 32(11), 2210-2216.

Kulstad, P. M. (2008). Concepción de la Vega $1495-$ 1564: A Preliminary Look at Lifeways in the Americas' First Boom Town, (master thesis, University of Florida). Disponible en http://etd. fcla.edu/UF/UFE0022363/kulstad_p.pdf

Kulstad, P.M. (2019). Hispaniola - Hell or Home?: Decolonizing Grand Narratives about Intercultural Interactions at Concepción de la Vega (14941564), (doctoral dissertation). Leiden, Holanda: University of Leiden. 
Laffoon, J. E., Plomp, E., Davies, G. R., Hoogland, M. L. \& Hofman, C. L. (2015). The movement and exchange of dogs in the prehistoric Caribbean: An isotopic investigation. International Journal of Osteoarchaeology, 25(4), 454-465.

Laffoon, J. E., Hoogland, M. L., Davies, G. R. \& Hofman, C. L. (2019). A multi-isotope investigation of human and dog mobility and diet in the pre-colonial Antilles. Environmental Archaeology, 24(2), 132-148.

Laffoon, J. E. \& Leppard, T. P. (2019). 87 Sr/86 Sr data indicate human post-juvenile residence mobility decreases over time-elapsed since initial Holocene island colonization in the Pacific and Caribbean. Archaeological and Anthropological Sciences, 11(5), 1757-1768.

Laffoon, J.E., Pagán-Jiménez, J.R., Weston, D.A., Valcárcel Rojas, R., \& Hoogland, M.L.P. (in prep.). Changing lifeways and deathways. In C.L. Hofman, J. Ulloa Hung, G.R. Davies, \& U. Brandes (Eds.), NEXUS1492: New World Encounters in a Globalizing World. Leiden: Brill.

López Belando, A. (2012) "El Sitio Arqueológico de Playa Grande, Río San Juan, María Trinidad Sánchez: Informe de Las Excavaciones Arqueológicas Campaña 2011-2012.” Manuscrito inédito. Santo Domingo: Museo del Hombre Dominicano.

Martinón-Torres, M., Rojas, R. V., Cooper, J. \& Rehren, T. (2007). Metals, microanalysis and meaning: a study of metal objects excavated from the indigenous cemetery of El Chorro de Maíta, Cuba. Journal of Archaeological Science, 34(2), 194-204.

Mickleburgh, H. L., Laffoon, J. E., Pagán Jiménez, J. R., Mol, A. A., Walters, S., Beier, Z. J. \& Hofman, C. L. (2019). Precolonial/early colonial human burials from the site of White Marl, Jamaica: new findings from recent rescue excavations. International Journal of Osteoarchaeology, 29(1), 155-161.
Mickleburgh, H. L. \& Wescott, D. J. (2018). Controlled experimental observations on joint disarticulation and bone displacement of a human body in an open pit: implications for funerary archaeology. Journal of Archaeological Science: Reports, 20, 158-167.

Mira Caballos, E (1997). El indio antillano: repartimiento, encomienda y esclavitud (1492-1541). Bogotá-Sevilla: Muñoz Moya Editor.

Mira Caballos, E. (2013). Aculturación a la inversa: la indianización de los conquistadores. Hombres de a Piey de a Caballo: Conquistadores, Cronistas, Misioneros en la América Colonial de los Siglos XVI y XVII. Nueva York, Estados Unidos: IDEA. Disponible en http://dadun. unav.edu/handle/10171/34141.

Moreno-Estrada, A., Gravel, S., Zakharia, F., McCauley, J. L., Byrnes, J. K., Gignoux, C. R.\& Eng, C. (2013). Reconstructing the population genetic history of the Caribbean. PLoS genetics, 9(11), e1003925.

Moreno del Río, J. L. (2012). Ganadería, plantacionesy comercio azucarero antillano. Siglos XVI y XVIII. Santo Domingo: Academia Dominicana de la Historia.

Mol, A. A. (2011). The Gift of the "Face of the Living»: Shell faces as social valuables in the Caribbean Late Ceramic Age. Journal de la société des américanistes, 97(97-2), 7-43.

Moya Pons, F (2008). Historia del Caribe (Azúcar $y$ plantaciones en el mundo atlántico). Santo Domingo, República Dominicana: Ediciones Ferilibro.

Ortega, E. \& Fondeur, C. (1978). Estudio de la cerámica del periodo indo-hispano de la antigua Concepción de La Vega. Santo Domingo, República Dominicana: Fundación Ortega Álvarez.

Olsen Bogaert, H., Duval, S. \& Coste, F. (2011). Sitio Arqueológico No. 11. Investigación Estructuras Coloniales. Reporte de Investigación. Pueblo Viejo Dominicana Corporation, Proyecto Pueblo Viejo, Santo Domingo, República Dominicana: Museo del Hombre Dominicano. 
Pagán-Jiménez, J. R. (2013). Human-plant dynamics in the precolonial Antilles (pp. 391-406). Oxford: Oxford University Press.

Pérez Iglesias, L. \& Valcárcel Rojas, R. (2015). Restos de cerdo en los contextos arqueológicos de El Chorro de Maíta, Holguín, Cuba. Etnobiología, 12(2), 39-49.

Pesoutová, J. \& Hofman, C.L. (2016) La contribución indígena a la biografía del paisaje cultural de la República Dominicana. Una revisión preliminar. En J. Ulloa Hung \& R. Valcárcel Rojas (eds.). Indigenas e indios en el Caribe. Presencia, legado y estudio, (pp. 115-148). Santo Domingo, República Dominicana: Instituto Tecnológico de Santo Domingo.

Pesoutová, J. (2019). Indigenous ancestors and healing landscapes: cultural memory and intercultural communication in the Dominican Republic and Cuba (doctoral dissertation). Leiden, Holanda: University of Leiden.

Prieto Vicioso, E. (2007). La arquitectura indígena en La Española. Clio, 175, 113-150.

Rivera-Collazo, I. C. (2019). Severe Weather and the Reliability of Desk-Based Vulnerability Assessments: The Impact of Hurricane María to Puerto Rico's Coastal Archaeology. The Journal of Island and Coastal Archaeology, $1-20$.

Reyes Cardero, J.M (2018). Supervivencia e impronta de indios y sus descendientes en el Santiago de Cuba colonial (siglo XVI al XIX). En R. Valcárcel Rojas, \& J. Ulloa Hung (eds.). De la desaparición a la permanencia. Indígenas e indios en la reinvención del Caribe, (pp. 83120). Santo Domingo, República Dominicana: INTEC y Fundación García Arévalo.

Roca Barea, M. E. (2016). Imperiofobia y leyenda negra: Roma, Rusia, Estados Unidos y el Imperio español. Madrid, España: Siruela.

Roura Âlvarez, L. (2018). Indios de La Habana: mestizaje y transculturación. En R. Valcárcel Rojas $\&$ J. Ulloa Hung (eds.). De la desaparición a la permanencia. Indígenas e indios en la reinvención del Caribe, (pp. 121-144). Santo Domingo: INTEC y Fundación García Arévalo.
Rodríguez Ramos. R. (2010). What is the Caribbean? An archaeological perspective. Journal of Caribbean Archaeology, 3, 19-51.

Sankatsing, N. T. \& Hofman, C. L. (2018). Engaging Caribbean island communities with indigenous heritage and archaeology research. JCOM: Journal of Science Communication, 17, 10.

Samson, A. V. M. (2010). Renewing the house: trajectories of social life in the yucayeque (community) of El Cabo, Higüey, Dominican Republic, AD 800 to 1504. Leiden, Holanda: Sidestone Press.

Schroeder, H., Sikora, M., Gopalakrishnan, S., Cassidy, L. M., Delser, P. M., Velasco, M. S., ... \& Allentoft, M. E. (2018). Origins and genetic legacies of the Caribbean Taino. Proceedings of the National Academy of Sciences, 115(10), 2341-2346.

Scott, R. B., Neyt, B., Hofman, C. \& Degryse, P. (2018). Determining the Provenance of Cayo Pottery from Grenada, Lesser Antilles, Using Portable X-Ray Fluorescence Spectrometry. Archaeometry, 60(5), 966-985.

Siegel, P. E., Hofman, C. L., Bérard, B., Murphy, R., Ulloa Hung, J., Valcárcel Rojas, R. \& White, C. (2013). Confronting Caribbean heritage in an archipelago of diversity: Politics, stakeholders, climate change, natural disasters, tourism, and development. Journal of field archaeology, 38(4), 376-390.

Sonnemann, T., Ulloa Hung, J. \& Hofman, C. (2016). Mapping indigenous settlement topography in the Caribbean using drones. Remote Sensing, 8(10), 791.

Stevens-Arroyo, A. (1993). The Inter-Atlantic Paradigm: The Failure of Spanish Medieval Colonization of the Canary and Caribbean Islands. Comparative Studies in Society and History, 35(3), 515-543. doi: 10.1017/ S0010417500018569.

Sued Badillo. J. (1978). Los caribes, realidad ofábula: Ensayo de rectificación histórica. Río Piedras, Puerto Rico: Editorial Antillana. 
Sued-Badillo, J. (1992). Christopher Columbus and the enslavement of the Amerindians in the Caribbean. Monthly Review, 44(3), 71-103.

Tejera Gaspar, A. \& Aznar Vellejo, E. (1992) Lesson from the Canaries, first contact between Europeans and Canarians c. 1312-1477. Antiquity, 66(250), 120-129.

Ulloa Hung, J. (2014). Arqueología en la Linea Noroeste de La Española. Paisajes, cerámicas e interacciones. Santo Domingo, República Dominicana: Instituto Tecnológico de Santo Domingo.

Ulloa Hung. J. \& Herrera, M.E. (2015). Investigaciones arqueológicas en el norte de La Española. Entre viejos esquemas y nuevos datos. Boletín del Museo del Hombre Dominicano, 42, 33.

Ulloa Hung, J. \& Valcárcel Rojas R. (2016). Reseńa del segundo seminario: Arqueología, Antropología e Historia del Primer Encuentro Colonial en las Américas. Ciencia y Sociedad, 41(4), 903-905.

Ulloa Hung, J. \& Valcárcel, R. R. (2016a). Indigenas e indios en el Caribe: presencia, legado y estudio. Santo Domingo, República Dominicana: INTEC.

Ulloa Hung, J. \& Valcárcel Rojas, R. (2018). Reseña del Tercer Seminario "Arqueología, Antropología e Historia en el espacio del primer encuentro colonial en Las Américas" (15 noviembre de 2018). Ciencia Y Sociedad, 43(4), 83-86. doi: https://doi.org/10.22206/ cys.2018.v43i4.

Ulloa Hung, J., Valcárcel Rojas, R., Antczak, A. T., Ernest, M. \& Hofman, C.L (2019). Social Networks and Adaptation in the Colonial Caribbean. En preparación.

Valcárcel Rojas, R., Samson, A. V. \& Hoogland, M. L. (2013). Indo-Hispanic dynamics: from contact to colonial interaction in the Greater Antilles. International Journal of Historical Archaeology, 17(1), 18-39.

Valcárcel Rojas, R., Hofman, C.L. \& Hoogland, M.L. (2014). Indios. Arqueología de una nueva identidad. Indios en Holguin, (pp. 20-42). Holguín, Cuba: Editorial La Mezquita
Valcárcel Rojas, R. (2016). Archaeology of early colonial interaction at El Chorro de Maita, Cuba. Florida, Estados Unidos: University Press of Florida.

Valcárcel Rojas, R\& Ulloa Hung, J. (2018). De la desaparición a la permanencia. Indígenas e indios en la reinvención del Caribe. Santo Domingo: INTEC y Fundación García Arévalo.

Valcárcel Rojas, R. (2019). Revisitando el universo colonial. Arqueología de la interacción entre indígenas y europeos en Las Antillas. En L. S. Domínguez, P. P. Funari, A. Guida Navarro (eds.). Arqueología del contacto en Latinoamérica, (pp. 397-422). Sao Paulo, Brasil: Paco P editorial.

Valcárcel Rojas, R.; Ulloa Hung, J. \& Torres Rodríguez, D. (2018). Más allá del oro. El tesoro del legado indígena en la cultura e identidad caribeña. INTEC Hacia el futuro 42(1), 44-47.

Vega, B. (1981). La herencia indígena en la cultura dominicana de hoy. Ensayos sobre cultura dominicana, (pp. 11-53). Santo Domingo, República Dominicana: Museo del Hombre Dominicano.

Vega, B. (1990). Los Cacicazgos de La Española. Santo Domingo: Fundación Cultural. Dominicana.

Veloz Maggiolo, M., Ortega, E., \& Caba Fuentes, A. (1981). Los modos de vida meillacoides y sus posibles orígenes: un estudio interpretativo. Santo Domingo, República Dominicana: Museo del Hombre Dominicano.

Veloz Maggiolo, M. \& Ortega Álvarez, E. (1980) Nuevos hallazgos arqueológicos en la costa norte de Santo Domingo. Boletín del Museo del Hombre Dominicano, 13, 11-48.

Weston, D., \&Valcárcel Rojas, R. (2016). Communities in contact: health and paleodemography at El Chorro de Maíta, Cuba. En Ivan Roksandic (ed.). Cuban Archaeology in The Caribbean, (pp. 83-105). Gainesville, Estados Unidos: University of Florida Press. 
Ziesemer, K. A, A. E. Mann, K. Sankaranarayanan, Sankaranarayanan, H. Schroeder, A. T. ozga, E. Brandt, E. Zaura, A. Waters-Rist, M. Hoogland, D. C. Salazar-García, M. Aldenderfer, C. Speller, J. Hendy, D. A. Weston, S. J. MacDonald, G.
H. Thomas, M. J. Collins, C. M. Lewis, C. L. Hofman, and C. Warinner (2015). Intrinsic challenges in ancient microbiome reconstruction using $16 \mathrm{~S}$ rRNA gene amplification. Scientific Reports 5, 16498.

\section{Datos de filiación}

Corinne L. Hofman. Profesora de arqueología del Caribe. Departamento de Arqueología de las Américas. Facultad de Arqueología de la Universdiad de Leiden. Tiene más de 30 años de experiencia en investigaciones arqueológicas en el Caribe y es Investigadora Principal del proyecto Nexus 1492 y del proyecto CaribTRAILS Caribbean Transdisciplinary Research. Archaeology of Indigenous Legacies Spinoza Koninklijk Instituut voor Taal-, Land en Volkenkunde (KITLV-KNAW)/ Royal Netherlands Institute of Southeast Asian and Caribbean Studies.

Jorge Ulloa Hung. Profesor Investigador del Instituto Tecnológico de Santo Domingo (INTEC) y Encargado del Departamanento de Arqueología del Museo del Hombre Dominicano. Además fue investigador de postdoctorado en el proyecto NEXUS 1492 y actualmente Senior Researcher en el proyecto CaribTRAILS Caribbean Transdisciplinary Research. Archaeology of Indigenous Legacies Spinoza Koninklijk Instituut voor Taal-, Land en Volkenkunde (KITLV). 